\title{
Biofilms: possible strategies for suppression in chronic wounds
}

Percival SL, Cutting KF (2009) Biofilms: possible strategies for suppression in chronic wounds. Nursing Standard. 23, 32, 64-72. Date of acceptance: February 192009.

Summary
Biofilms can delay wound healing significantly. The aim of this article
is to highlight strategies that could be used to treat chronic wounds
containing biofilms. Antibiofilm agents, their modes of action and
efficacy in suppressing biofilms are discussed.
Authors
Steven L Percival is adjunct professor of microbiology, School of
Medicine, University of West Virginia, Morgantown, United States,
and Keith F Cutting is principal lecturer, Buckinghamshire New
University, Buckinghamshire. Email: keith.cutting@bucks.ac.uk
Keywords
Biofilms; Chronic wound infections; Micbrobial bioburden;
Wound healing
These keywords are based on the subject headings from the British
Nursing Index. This article has been subject to double-blind review.
For author and research article guidelines visit the Nursing Standard
home page at nursingstandard.rcnpublishing.co.uk. For related
articles visit our online archive and search using the keywords.

THE MICROBIAL BIOBURDEN of a chronic wound is thought to be one of the most important barriers to wound healing (White and Cutting 2006, Ryan 2007, Tan et al 2007). Historically, standard microbiology laboratory operating procedures in wound care studies have reported only on planktonic or free-floating microorganisms to help guide management strategies. More recently, research has highlighted that resident or sessile (attached) microorganisms, which are phenotypically and genetically different to the planktonic (free-floating) microorganisms, are compartmentalised in the chronic wound environment (Percival and Bowler 2004a, 2004b, James et al 2008).

A biofilm is a community of microorganisms attached to each other or to a surface and encased in an extracellular polymeric substance (EPS), with increased resistance to cellular and chemical attack. Biofilms are likely to cause a significant delay in healing and clinicians need to consider their resistance to antimicrobials if healing is to be achieved.
A misunderstanding of the role microorganisms play in chronic wound healing may result in sub-optimal management of chronic wounds and delayed healing in some acute wounds (Costerton and Stewart 2001, Costerton et al 2003).

This article highlights possible approaches to suppressing biofilms in chronic wounds, thus allowing the host defence mechanisms to prevail.

\section{The biofilm concept}

As $99 \%$ of microorganisms found in their native habitats persist in a biofilm state, this mode of microbial growth is applied to the wound environment (Percival and Rogers 2005, Ngo et al 2007, James et al 2008). Planktonic bacterium, coaggregates (clusters) of bacteria, or fragments of biofilm (clusters of bacteria encased within an EPS) often attach to a surface, multiply and grow (Percival et al 2007, Thomas 2008).

Medical biofilms Up to $80 \%$ of human infections are thought to be related to pathogenic biofilms (Anon 1997). However, clinicians have begun to appreciate that many persistent infections are caused by biofilms. Many chronic infections influenced or induced by a biofilm, for example prostatitis, endocarditis and osteomyelitis, have been found to persist indefinitely (Percival and Bowler 2004b). It seems plausible therefore to hypothesise that biofilms have a fundamental role in chronic wound infections.

Implications of biofilms As bacteria in the biofilm multiply they continually produce 'pheromones', called quorum-sensing molecules (Box 1). These are significant in the formation of a biofilm and in the development of the bacterial community. Changes in a chronic wound biofilm, induced by quorum-sensing molecules, enhance the recalcitrance of the biofilm to antimicrobials (Sauer et al 2002). With an array of physical and metabolic defences, the biofilm has an enhanced resistance to antimicrobials including antibiotics, antiseptics and host defence mechanisms (Costerton and Stewart 2001, Costerton et al 2003, Burmølle et al 2006, Marion et al 2006). Many mechanisms inherent to the biofilm, 


\section{art \&o science tissue viability supplement}

including physical and chemical heterogeneity, interspecies co-operation, and intercellular structure, contribute to this enhanced recalcitrance to antimicrobials (Xu et al 2000, Fux et al 2005, Burmølle et al 2006, Shen et al 2006, Chang et al 2007).

Most microbial metabolism and bacterial divisions occur in cells located near the biofilm surface. These active bacterial cells are thought to reproduce constantly and disperse from the biofilm at a high rate. These metabolically active cells have been shown to be the most vulnerable sub-population in the biofilm to antimicrobials, particularly antibiotics and host defences (Costerton et al 2003). Contrary to this, microorganisms, specifically bacteria found deep in the extracellular matrix of the biofilm, have been found to be protected from external perturbations, are less metabolically active and more recalcitrant to antimicrobial management practices (Xu et al 2000, Lewis 2007). In addition, microbial cells found deep within the biofilm have the ability to reconstitute the community of the biofilm extremely quickly, particularly during periods of extreme stress (Lewis 2007).

Based on the above findings, the management of a biofilm community is significantly more challenging than that traditionally used in planktonic-based wound care.

\section{Theory and practice of wound biofilms}

When skin is broken a relatively 'immature' wound is formed and the primary bacterial

\section{BOX 1}

\section{Glossary}

- Colonisation - the presence of bacteria in increasing numbers in the wound without inducing a host reaction. It is not possible to differentiate clinically between contamination and colonisation.

- Contamination - the presence of bacteria in a wound without inducing a host reaction.

- Matrix metalloproteases - proteases that may be endogenous or exogenous in origin and break down protein, for example collagen.

- Planktonic - free-floating microorganisms not attached to a surface.

- Proinflammatory cytokines - protein molecules derived from the immune system that amplify the inflammatory response.

- Quorum sensing - measuring the bacterial population concentration through the expression of bacterial signalling molecules. When a 'quorum' is reached, specific biological activities, for example expression of virulence factors are activated.

- Sessile - microorganisms attached to a surface.

66 april $15:$. vol 23 no $32: .2009$ defence barrier is initially compromised (Niyonsaba et al 2006). The host's primary objective is to prevent the bacteria that have contaminated the wound from increasing in number and inducing infection. Typically, the host easily fends off potential pathogens through inflammation (proinflammatory cytokines, matrix metalloproteases, phagocytosis and degranulation of neutrophils). However, a number of host factors promote the establishment of a chronic wound and infection, including poor perfusion, malnutrition, foreign body presence, pressure, repetitive trauma, hyperglycaemia and white blood cell dysfunction.

If a biofilm becomes established in a wound, it will be difficult to suppress, particularly in an immunocompromised individual (Costerton et al 2003). Consequently, the microorganisms and their extracellular components within the biofilm will prolong the state of acute inflammation indefinitely, delaying the normal healing process.

Clinicians often focus on the number of culturable bacteria that are present in the wound as this frequently correlates with the degree of immune stimulation (classic signs of acute infection) seen in the patient (Dow 2001). However, many clinical biofilm bacteria cannot be cultured and so these bacteria can often be overlooked using traditional microbiological techniques (Costerton et al 2003).

Sharp debridement of devitalised tissue promotes healing by removing tissue that not only supports microbial proliferation (the biofilm) but also reduces the efficacy of topical therapies. Consequently, debridement should be performed at weekly intervals in chronic wounds containing devitalised tissue and biofilm (Wolcott et al 2009), although this should only be carried out by those who are qualified to carry out this skill. Debridement is thought not only to remove microorganisms but also to expose deeper host defences, therefore enhancing their efficacy. However, debridement alone in the authors' opinion is not sufficient to manage the majority of chronic wounds because of the nature of biofilm removal and re-establishment. Other concomitant strategies such as antimicrobials should be considered as an adjunct therapy (Schultz et al 2004).

Some studies have shown that antimicrobial agents sometimes work effectively to suppress the metabolically active cells in a biofilm (Flemming et al 2009). However, it is important to acknowledge that no single strategy has yet proven to be consistently effective at suppressing the entire biofilm. For example, infection often reoccurs following the administration of a course of antibiotics. This is because antibiotics

NURSING STANDARD 


\section{art ※o science tissue viability supplement}

are only effective in transiently suppressing rapidly growing cells, which are generally located on the outermost surface of the biofilm. Recalcitrant microbial cells found deep in the biofilm will persist.

Shortcomings exist in the use of single or sequential treatment strategies. In the authors' experience, concurrent management strategies will increase the likelihood of prolonging suppression of the biofilm. Such extensive suppression of the biofilm is essential to foster sufficient healing (Costerton et al 2003). There are no visible clinical signs to indicate the presence of a biofilm, however if other causes of delayed wound healing such as smoking and poor nutrition have been ruled out, then a chronic infection (biofilm) is usually suspected .

\section{Management strategies}

Many commercially available wound dressings are not inherently antimicrobial. However, some

\section{TABLE 1}

\begin{tabular}{|c|c|c|}
\hline \multicolumn{3}{|c|}{ Potential antibiofilm agents } \\
\hline Agent & Mode of action & Usage \\
\hline Lactoferrin & $\begin{array}{l}\text { Blocks the attachment } \\
\text { of planktonic bacteria to a } \\
\text { surface. Blocking the initial } \\
\text { attachment of bacteria } \\
\text { stops the first step in } \\
\text { biofilm formation (Singh } \\
\text { et al 2002) }\end{array}$ & $\begin{array}{l}\text { Bovine lactoferrin is a } \\
\text { protein used in the } \\
\text { meatpacking industry } \\
\text { to protect exposed meat } \\
\text { from bacterial biofilm } \\
\text { formation }\end{array}$ \\
\hline Xylitol & $\begin{array}{l}\text { Interferes with biofilm } \\
\text { formation (Katsuyama et al } \\
\text { 2005) }\end{array}$ & $\begin{array}{l}\text { Xylitol is a five-carbon } \\
\text { alcohol sugar used in } \\
\text { chewing gum. } \\
\text { It has been shown to } \\
\text { reduce the incidence of } \\
\text { dental caries (Burt 2006) }\end{array}$ \\
\hline Gallium & $\begin{array}{l}\text { Interferes with bacterial } \\
\text { iron metabolism pathways } \\
\text { (Kaneko et al 2007) }\end{array}$ & $\begin{array}{l}\text { Gallium nitrate is approved } \\
\text { by the Food and Drug } \\
\text { Administration and can be } \\
\text { used intravenously }\end{array}$ \\
\hline Dispersin B & $\begin{array}{l}\text { Targets the extracellular } \\
\text { polymeric substance of } \\
\text { some types of biofilm and } \\
\text { works to degrade the } \\
\text { community structure of the } \\
\text { biofilm (Itoh et al 2005) }\end{array}$ & $\begin{array}{l}\text { Dispersin B is a bacterial } \\
\text { enzyme but is not presently } \\
\text { used commercially }\end{array}$ \\
\hline Honey & $\begin{array}{l}\text { Possesses antibacterial } \\
\text { activity (Molan 1999, 2006) } \\
\text { and modulates monocytic } \\
\text { cell activity (Tonks et al } \\
\text { 2001, 2003) }\end{array}$ & $\begin{array}{l}\text { Honey has shown some } \\
\text { potential against in vitro } \\
\text { biofilms (Okhiria et al } \\
\text { 2004) }\end{array}$ \\
\hline
\end{tabular}

68 april $15::$ vol 23 no $32:: 2009$ wound dressings have been shown to help reduce the bacterial load at the wound surface through sequestration (binding) of bacteria (Mertz and Eaglstein 1984, White et al 2006). Consequently, wound dressings should be selected carefully to help reduce the risk of biofilm growth and therefore further proliferation on and within the wound.

The modes of action of various antimicrobial agents differ. However, their effects are similar, in that they impair the metabolism or integrity of microorganisms by stopping or substantially reducing cell division (microbiostatic) or by killing microorganisms directly (microbiocidal). The most recently designed antibiofilm agents often work without impairing microbial growth, reproduction or cell integrity but by breaking up the biofilm, removing essential nutrients or metal ions, or interfering with microbial community interactions such as quorum sensing (Singh et al 2002, Costerton et al 2003, Kaneko et al 2007). These agents are not yet available as they are experimental developments. Once approved by the regulatory authorities they will provide a more effective approach to wound biofilm management. However, they will not be a 'one dose' or 'one application' only approach but will need to be repeated or sustained in line with current antibiotic and antiseptic use.

Systemic antibiotic treatment is used in chronic wounds in situations where there is significant deep tissue wound infection or a risk of septicaemia. However, systemic antibiotics have been shown to have a low efficacy rate when biofilms are present (Moss et al 1990, Marr et al 1997). The use of antibiotics is problematic in ischaemic wounds. This is because the therapeutic concentrations that are routinely used may not reach the site of infection at the therapeutic dose. However, systemic antibiotics have been shown to contribute to the clinical management regimen of many wound biofilms by suppressing the cells at the outermost region of the biofilm (Xu et al 2000).

Topical antiseptics can also help to reduce the wound bioburden and biofilm, particularly where there is a concurrent infection or an increased risk of infection.

In the authors' opinion, the efficacy of antimicrobial agents can be substantially enhanced when combined with other management strategies, specifically debridement in conjunction with an appropriate wound dressing.

Antimicrobial agents It is plausible to suggest that antimicrobial agents could act prophylactically to suppress biofilm development. However, some non-selective antimicrobials may be detrimental to wound healing by harming the host's cells, for example alcohols, hydrogen peroxide, carbolic acid, 


\section{art \&o science tissue viability supplement}

sodium hypochlorite and acetic acid. Selective antimicrobials such as molecular iodine and ionic silver are more suitable for chronic wounds. Iodine Iodine has been used for many years as a wound antiseptic (Cooper 2007). However, high doses of iodine can be detrimental to host healing (Kramer 1999, Wilson et al 2005). Cadexomer iodine can be used to suppress biofilms without causing significant host cell damage (Akiyama et al 2004).

Ionic silver Ionic silver is a beneficial antimicrobial for use in wound care, particularly for biofilm-based management strategies. Ionic silver has a broad range of efficacy against many microorganisms (Russell and Hugo 1994, Lansdown et al 1997). In addition, a number of silver dressings have been shown to prevent biofilm formation in vitro (Percival et al 2007) and also have in vivo benefits (Fong and Wood 2006). Honey In vitro evidence shows that honey is effective against a range of multi-resistant organisms including meticillin-resistant Staphylococcus aureus, vancomycin-resistant enterococci and multi-resistant Gram-negative organisms including Pseudomonas aeruginosa (George and Cutting 2007), and can surpass the use of antibiotics or antiseptics in previously unresponsive wounds (Dunford et al 2000). Irish et al (2006) demonstrated the effectiveness of honey in preventing biofilm formation. Okhiria et al (2004) found disruption of pseudomonal biofilms (in vitro) following application of honey. Honey also has potential as an antibiofilm agent (Table 1).

Antibiofilm agents The use of antibiofilm agents are considered by many to be beneficial to wound management as they have been shown to be less cytotoxic than many traditional antimicrobials. These include

\section{References}

\section{Akiyama $H$, Oono $T$, Saito $M$, Iwatsuki K (2004) Assessment of cadexomer iodine against Staphylococcus aureus biofilm in vivo and in vitro using confocal laser scanning microscopy. Journal of Dermatology. 31, 7, 529-534. \\ Anon (1997) Minutes of the National Advisory Dental and Craniofacial Research Council - 153rd Meeting. National Institutes of Health. September 9.}

\section{Burmalle M, Webb JS, Rao D,} Hansen LH, Sørensen SJ, Kjelleberg S (2006) Enhanced biofilm formation and increased resistance to antimicrobial agents and bacterial invasion are caused by synergistic interactions in multispecies biofilms. Applied and Environmental Microbiology. 72 6. 3916-3923.

Burt BA (2006) The use of sorbitol- and xylitol-sweetened chewing gum in caries control. Journal of the American Dental Association. 137, 2, 190-196.

Chang WS, van de Mortel $M_{t}$ Nielsen L, Nino de Guzman G Li X, Halverson LJ (2007) Alginate production by Pseudomonas putida creates a hydrated microenvironment and contributes to biofilm architecture and stress tolerance under water-limiting conditions. Journal of Bacteriology. $189,22,8290-8299$.

Cooper RA (2007) Iodine revisited. International Wound

\section{Journal. 4, 2, 124-137.}

Costerton JW, Stewart PS

(2001) Battling biofilms. Scientific American. 285, 1, 74-81.

Costerton W, Veeh R, Shirtliff M, Pasmore M, Post C, Ehrlich G (2003) The application of biofilm science to the study and control of chronic bacterial infections. Journal of Clinical Investigation. 112, 10, 1466-1477.

Dow G (2001) Infection in chronic wounds. In Krasner DL, Rodeheaver GT, Sibbald RG (Eds) Chronic Wound Care: A Clinical Source Book for Healthcare Professionals. HMP Communications, Pennsylvania 343-356.

Dunford C, Cooper R, Molan P White R (2000) The use of honey in wound management. Nursing Standard. 15, 11, 63-68.

Flemming $\mathbf{K}$, Kingenberg $\mathbf{C}$, Cavanagh JP et al (2009) High in vitro antimicrobial activity of synthetic antimicrobial peptidomimetics against staphylococcol biofilms. Journal of Antimicrobial Chemotherapy. 63, 1, 136-145.

\section{Fong J, Wood F (2006)}

Nanocrystalline silver dressings in wound management: a review. International Journal of Nanomedicine. 1, 4, 441-449.

Fux CA, Costerton JW, Stewart PS, Stoodley P (2005) Survival strategies of infectious biofilms. Trends in Microbiology. 13, 1, 34-40.
George NM, Cutting KF (2007) Antibacterial honey (Medihoney ${ }^{\mathrm{TM}}$ ) in-vitro activity against clinical isolates of MRSA, VRE, and other multiresistant gram-negative organisms including Pseudomonas aeruginosa. Wounds. 19, 9, 231-236.

Irish J, Carter D, Blair S (2006) Honey Prevents Biofilm Formation in Staphylococcus Aureus. Poster presentation. 8th Asian Apicultura Association Conference. March 20-24, Perth, Australia.

Itoh $Y$, Wang $X$, Hinnebusch BJ Preston JF 3rd, Romero T (2005) Depolymerization of beta- 1 ,

6-N-acetyl-D-glucosamine disrupts the integrity of diverse bacterial biofilms. Journal of Bacteriology. $187,1,382-387$.

ames GA, Swogger E, Wolcott $R$ et $\boldsymbol{a l}$ (2008) Biofilms in chronic wounds. Wound Repair and Regeneration. 16, 1, 37-44.

Kaneko Y, Thoendel M, Olakanmi 0, Britigan BE, Singh PK (2007)

The transition metal gallium disrupts Pseudomonas aeruginosa iron metabolism and has antimicrobial and antibiofilm activity. Journal of Clinical Investigation. 117, 4, 877-888.

Katsuyama M, Kobayashi Y Ichikawa H et al (2005) A novel method to control the balance of skin microflora Part 2. A study to assess the effect of a cream containing farnesol and xylito on atopic dry skin. Journal of
Dermatological Science. 38, 3, 207-213

Kramer SA (1999) Effect of povidone-iodine on wound healing: a review. Journal of Vascular Nursing. 17, 1, 17-23.

\section{Lansdown AB, Sampson B,}

Laupattarakasem $P$

Vuttivirojana A (1997) Silver aids healing in the sterile skin wound: experimental studies in the laboratory rat. British Journal of Dermatology. 137, 5, 728-735.

Lewis K (2007) Persister cells, dormancy and infectious disease. Nature Reviews Microbiology. 5, 1. 48-56.

Lu TK, Collins JJ (2007)

Dispersing biofilms with engineered enzymatic bacteriophage.

Proceedings of the Nationa Academy of Sciences of the United States of America. 104, 27, 11197-11202.

Marion K, Freney J, James G, Bergeron E, Renaud FN Costerton JW (2006) Using an efficient biofilm detaching agent: an essential step for the improvement of endoscope reprocessing protocols. Journal of Hospital Infection. 64, 2, 136-142.

Marr KA, Sexton DJ, Conlon PJ, Corey GR, Schwab SJ Kirkland KB (1997)

Catheter-related bacteremia and outcome of attempted catheter salvage in patients undergoing hemodialysis. Annals of Internal 


\section{art \&o science tissue viability supplement}

lactoferrin (Singh et al 2002), xylitol (Katsuyama et al 2005), gallium (Kaneko et al 2007) and Dispersin B (Lu and Collins 2007). Evidence regarding the benefits of such agents to wound healing is slowly beginning to gain momentum. Agents that have been used as antibiofilm agents in wound care can be found in Table 1. These agents are still being evaluated and are not yet available in clinical practice.

\section{Conclusion}

The aim for the wound care provider is to establish the best management strategies possible for each individual patient. To achieve this, clinicians need to be familiar with antimicrobial and antibiofilm agents. The basis of managing biofilms is frequent removal of the biofilm from the surface of the wound. This can be achieved with either sharp debridement (curette), or formal surgical debridement. As biofilms reconstitute quickly following invasive debridement, suppressing their regrowth and reconstitution using multiple antimicrobial management strategies is warranted, including wound cleansers, topical antimicrobials and advanced wound dressings. Such strategies may work synergistically to help suppress and reduce the regrowth of the biofilm. A 'rotating' regimen of selective antimicrobials may be advantageous in biofilm-based wound management. Systemic antibiotics may also help to suppress further the biofilm.

For positive clinical outcomes it is important that all concurrent barriers to healing should be addressed. This will help to augment the host's defences which, when working optimally, provide the best strategies to help manage a wound. Consequently, biofilm-based management is becoming fundamental to non-healing wounds NS

\section{Medicine. 127, 4, 275-280.}

Mertz PM, Eaglstein WH (1984)

The effect of a semiocclusive

dressing on the microbial population

in superficial wounds. Archives of

Surgery. 119, 3, 287-289.

Molan PC (1999) The role of honey

in the management of wounds.

Journal of Wound Care. 8, 8,

415-418.

Molan PC (2006) The evidence supporting the use of honey as a wound dressing. International Journal of Lower Extremity Wounds. 5, 1, 40-54.

Moss AH, Vasilakis C, Holley JL, Foulks CJ, Pillai K, McDowell DE (1990) Use of a silicone dual-lumen catheter with a Dacron cuff as a long-term vascular access for hemodialysis patients. American Journal of Kidney Diseases. 16, 3 211-215.

Ngo Q, Vickery K, Deva AK (2007) Pr21 role of bacterial biofilms in chronic wounds. ANZ Journal of Surgery. 77, Suppl 1, A66.

Niyonsaba F, Nagaoka I, Ogawa H (2006) Human defensins and cathelicidins in the skin: beyond direct antimicrobial properties. Critical Reviews in Immunology. $26,6,545-576$

Okhiria 0, Henriques A, Burton N, Peters A, Cooper RA (2004) The Potential of Manuka Honey for the Disruption of Biofilms Produced by Strains of Pseudomonas Aeruginosa
Isolated from Wounds. Poster presentation. 155th Meeting of the Society for General Microbiology. September 6-9, Dublin.

Percival SL, Bowler PG (2004a) Biofilms and their potential role in wound healing. Wounds. 16, 7 234-240.

Percival SL, Bowler P (2004b) Understanding the effects of bacterial communities and biofilms on wound healing. www.worldwidewounds.com/2004/july/Percival/

Community-Interactions-

Wounds.html (Last accessed: April 2 2009.)

Percival SL, Rogers AA (2005)

The significance and role of biofilms in chronic wounds. In McBain A Allison D, Pratten J, Spratt D, Upton M, Verran J (Eds) Biofilms:

Persistence and Ubiquity. The Biofilm Club 7th Meeting of the Biofilm Club, Gregynog Hall, Powys. September 7-9. 171-178.

Percival SL, Bowler PG, Dolman J

(2007) Antimicrobial activity of silver-containing dressings on wound microorganisms using an in vitro biofilm model. International Wound Journal. 4, 2, 186-191.

Russell AD, Hugo WB (1994) Antimicrobial activity and action of silver. Progress in Medicinal Chemistry. 31, 351-370.

Ryan TJ (2007) Infection following soft tissue injury: its role in wound healing. Current Opinion in
Infectious Diseases. 20, 2, 124-128.

Sauer K, Camper AK, Ehrlich GD, Costerton JW, Davies DG (2002) Pseudomonas aeruginosa displays multiple phenotypes during development as a biofilm. Journa of Bacteriology. 184, 4, 1140-1154.

Schultz GS, Barillo DJ, Mozingo DW, Chin GA; Wound Bed Advisory Board Members (2004) Wound bed preparation and a brief history of TIME. International Wound Journal. 1, 1, 19-32.

Shen K, Sayeed S, Antalis P et al (2006) Extensive genomic plasticity in Pseudomonas aeruginosa revealed by identification and distribution studies of novel genes among clinical isolates. Infection and Immunity. 74, 9, 5272-5283.

\section{Singh PK, Parsek MR, Greenberg} EP, Welsh MJ (2002) A component of innate immunity prevents bacterial biofilm development. Nature. 417, 6888 552-555.

Tan J, Abisi S, Smith A, Burnand KG (2007) A painless method of ultrasonically assisted debridement of chronic leg ulcers: a pilot study. European Journal of Vascular and Endovascular Surgery. 33, 2 . 234-238.

Thomas J (2008) Wound microbiology. In Cutting KF (Ed) Advancing Your Practice: Understanding Wound Infection and the Role of Biofilms
Association for the Advancement of Wound Care. Malvern PA. 2-4.

Tonks A, Cooper RA, Price AJ, Molan PC, Jones KP (2001) Stimulation of TNF-alpha release in monocytes by honey. Cytokine. 14, 4, 240-242.

Tonks AJ, Cooper RA, Jones KP, Blair S, Parton J, Tonks A (2003) Honey stimulates inflammatory cytokine production from monocytes. Cytokine. 21, 5, 242-247.

White RJ, Cutting KF (2006)

Critical colonization: the concept under scrutiny. Ostomy/Wound Management. 52, 11, 50-56.

White RJ, Cutting K, Kingsley A (2006) Topical antimicrobials in the control of wound bioburden Ostomy/Wound Management. 52, 8, 26-58.

Wilson JR, Mills JG, Prather ID, Dimitrijevich SD (2005) A toxicity index of skin and wound cleansers used on in vitro fibroblasts and keratinocytes. Advances in Skin \& Wound Care. 18, 7, 373-378.

Wolcott RD, Kennedy JP, Dowd SE (2009) Regular debridement is the main tool for maintaining a healthy wound bed in most chronic wounds. Journal of Wound Care. 18 2, 54-56.

Xu KD, McFeters GA, Stewart PS (2000) Biofilm resistance to antimicrobial agents. Microbiology. $146,3,547-549$ 